\title{
L'HOMME L'Homme
}

Revue française d'anthropologie

175-176 | juillet-septembre 2005

Vérités de la fiction

Marcyliena Morgan, Language, Discourse and Power in African American Culture

Cambridge, Cambridge University Press, 2002, XIV +181 pages

\section{Barry Chevannes}

Traducteur : Danielle Menauge

\section{OpenEdition}

\section{Journals}

Édition électronique

URL : http://journals.openedition.org//homme/2058

DOI : $10.4000 /$ /homme 2058

ISSN : 1953-8103

Éditeur

Éditions de l'EHESS

\section{Édition imprimée}

Date de publication : 15 octobre 2005

Pagination : $517-520$

ISBN : 2-7132-2035-1

ISSN : 0439-4216

Référence électronique

Barry Chevannes, « Marcyliena Morgan, Language, Discourse and Power in African American Culture », L'Homme [En ligne], 175-176 | juillet-septembre 2005, mis en ligne le 30 novembre 2006, consulté le 24 septembre 2020. URL : http://journals.openedition.org//homme/2058 ; DOI : https://doi.org/10.4000/ Ihomme.2058

Ce document a été généré automatiquement le 24 septembre 2020.

(c) École des hautes études en sciences sociales 


\title{
Marcyliena Morgan, Language, Discourse and Power in African American Culture
}

\author{
Cambridge, Cambridge University Press, 2002, XIV + 181 pages
}

\section{Barry Chevannes}

Traduction : Danielle Menauge

\section{RÉFÉRENCE}

Marcyliena Morgan, Language, Discourse and Power in African American Culture, Cambridge, Cambridge University Press, 2002, XIV + 181 p. (« Studies in the Social and Cultural Foundations of Language »).

\section{NOTE DE L'ÉDITEUR}

Traduit de l'anglais (Jamaïque) par Danielle Menauge

1 TOUTE ÉTUDE sur la culture de la diaspora africaine, qui soulève des questions sur l'origine, risque de se trouver prise dans une controverse, dans la mesure où les spécialistes sont divisés sur le rôle du passé africain dans l'expérience vécue aux Amériques. Cependant, l'ouvrage Language, Discourse and Power in African American Culture sera objet de débat moins pour cette raison, bien que l'auteure reconnaisse et insiste sur les continuités africaines dans les styles verbaux de «l'anglais africainaméricain" (African American English, AAE), que pour sa position claire et sans ambiguïté sur le fait que l'AAE symbolise la culture des Africains-Américains.

2 «L'étude de la langue africaine-américaine consiste à étudier la façon dont les personnes d'origine africaine utilisent la langue comme une ressource culturelle qui, à son tour, représente, construit et médiatise la réalité sociale» (p. 1). En conséquence, 
ce livre met l'accent sur l'usage de l'AAE comme moyen de construction de l'identité « à travers des contextes culturels et sociaux » (p. 9). L'analyse de Marcyliena Morgan est fondée sur quinze années d'immersion dans la culture matérielle et linguistique des Africains-Américains, qu'il s'agisse d'hommes, de femmes, de jeunes, de familles, de communautés, dans le Nord à Chicago, au Mississippi dans le Sud, à Philadelphie dans l'Est, et à Los Angeles dans l'Ouest. Elle s'appuie également sur sa propre expérience en tant que membre de cette communauté d'expression. Aussi, sa voix n'est-elle pas celle d'un observateur lointain et détaché.

3 Le cœur de l'analyse se trouve dans les chapitres II à $V$, encadrés d'une part par une introduction qui affirme que les Africains-Américains constituent une communauté d'expression culturellement significative, et d'autre part, par une conclusion qui argumente en faveur de l'inclusion des Africains-Américains dans l'avenir de l'éducation américaine, opérée non pas sur la base de leur assimilation, mais sur celle de leur différence culturelle.

5 L'AAE est une langue créole, la langue d'un " peuple conquis qui n'est jamais revenu chez lui » (p. 13), un « contre-langage » en fait ; le produit d'une anti-société, créé pour résister à l'institution totalitaire de la plantation esclavagiste. Sur ce point et sur d'autres dans l'ouvrage, Marcyliena Morgan puise dans les travaux de Goffman, mais selon l'auteure, les institutions "souterraines" ne le sont que par rapport à la structure du pouvoir dominant; elles sont beaucoup plus « en surface » pour le groupe assujetti des Africains-Américains. De ce fait, ces institutions permettent l'action du groupe non dominant. «En réponse à l'injonction d'adopter l'attitude de l'opprimé, la culture africaine-américaine et l'anti-société ont sapé les valeurs, les attitudes et les croyances que la société dominante leur imposait [...] par l'usage de systèmes africains de détournement ». Ces systèmes ont fourni la possibilité - pour les locuteurs dans le cas de la langue - «de révéler une face sociale capable de résister et de contester la pratique de répression raciale»(p.24). Mais le développement de l'AAE n'a pas seulement été un transfert des normes africaines d'interaction; il a aussi reflété les expériences sociales et politiques de la plantation qui ont donné aux moyens oratoires une importance si intense "que "l'acte" de parler devenait potentiellement politique et hautement symbolique» (p. 25).

6 Le chapitre le plus important, bien qu'il ne soit pas le plus original, est de loin celui qui traite des formes verbales et discursives donnant à l'AAE son caractère culturel spécifique (chapitre II). Social face, indirectness, reading et signifying y sont expliqués et des exemples appropriés d'énonciations sont donnés. Le social face est une forme d'interaction en présence d'un public qui permet à l'orateur de sauver la face, d'être «cool» au lieu d'être «fool» (idiot). Cette attitude demande de l'habileté pour discerner les variations subtiles et les ambiguïtés des actes ou des énonciations symboliques et leur répondre avec esprit, éloquence et sens du rythme. Par conséquent, il s'agit d'un comportement culturel appris par socialisation. L'indirectness peut être dirigé (pointed) quand il s'adresse à quelqu'un par le biais d'un interlocuteur ridiculisé, ou alors servir d'appât (baited) quand il ne s'adresse à personne en particulier mais qu'il a l'intention de berner des cibles potentielles. Le reading est une confrontation verbale directe, qui simplement « dénigre quelqu'un de façon frontale [...] d'une manière peu subtile et sans ambiguïté » (p. 53). Marcyliena Morgan ajoute une variété qu'elle nomme reading dialect («leçon de dialecte»), qui est une forme de retournement de code pour marquer un 
point en opposant la grammaire de l'AAE à celle de l'anglais courant (General English, GE). Dans le signifying, jeu de mots pratiqué principalement par les adolescents masculins - et connu sous d'autres noms comme the dozens, snapping, sounding - une situation peu plausible est créée et les signes culturels sont utilisés de manière à interagir dans ce cadre, avec esprit, sarcasme, ironie et humour. Le caractère peu plausible est primordial, autrement le jeu deviendrait une véritable insulte. D'après Marcyliena Morgan, «la qualité la plus évidente de l'interaction africaine-américaine réside dans la manière dont l'action de l'orateur et celle de l'audience se combinent pour donner forme et évaluer à la fois le choix des styles dans les interactions et le choix des variantes à l'intérieur de chaque style» (p.55). De ce fait, toutes ces formes discursives exigent la présence d'une audience pour leur production, leurs significations et leur efficacité.

Un chapitre consacré aux locutrices africaines-américaines contribue à redresser à la fois le déséquilibre de la recherche qui s'appuie encore sur des exemples masculins comme si l'AAE était un langage africain-américain essentiellement masculin - et les tendances malheureuses de certaines études qui donnent une image négative de la femme africaine-américaine, au mieux en tant qu'observatrice ou supportrice des jeux masculins, au pire en tant que prédatrice sexuelle. Marcyliena Morgan affirme avec vigueur, que «les femmes africaines-américaines participent à la culture à tous les niveaux, y compris au développement des normes langagières, à l'introduction de nouveautés ainsi qu'à l'utilisation de toutes les variétés de l'AAE » (p. 87). Elle traite du problème de façon diachronique : les fillettes qui se socialisent les unes les autres en utilisant les formes sociales relatives à l'importance de « sauver la face » et à la manière de s'en réclamer ; les adolescentes qui se focalisent sur l'auteure de gros mots et qui par un processus de recherche confirmant les amitiés - se confrontent à l'offenseur et sauvent la face; les femmes adultes qui remplacent l'incitation par l'indirectness ou le signifying plus élaborés et par "le rire de la femme noire » - « une mise en accusation de la personne/du propos auxquels le rire se réfère » (p. 101).

Tout d'abord réticente, «parce que l'on a donné trop d'importance au langage de la jeunesse urbaine » (p. 111), Marcyliena Morgan s'aventure cependant dans le monde du hip-hop. Il en résulte l'argument que «la jeunesse urbaine a reconnu, admis et capitalisé les différentes formes discursives de l'AAE - directness, indirectness, reading dialect, signifying - et les a incorporées dans les façons de s'habiller, au niveau des corps et dans l'art. C'est dans cette mesure que le hip-hop représente l'intégration de l'expérience africaine-américaine dans la culture américaine » (p. 116). D'où le jeu de mots du sous-titre de ce chapitre: "Le langage de la jeunesse urbaine: Black par revendication populaire » ("Urban youth language : black by popular demand»-c'est moi qui souligne). Mais il s'agit de l'incorporation d'une identité qui n'est pas figée. Stuart Hall « devait avoir cette jeunesse en tête quand il décrivait l'identité comme le fait d'être soi-même sans rester le même » (p.117). Par conséquent, dans le hip-hop, à travers l'inversion et l'extension sémantiques, par les altérations morphologiques et les innovations lexicales, ou encore par le reading dialect et toutes les autres formes de manipulation des langages (AAE et GE), des identités localisées se construisent et se déconstruisent sans cesse dans une relation dynamique entre le contre-langage et le langage dominant. "Une fois que des mots sont introduits, leur devenir en tant qu'items lexicaux stables est déterminé soit par le fait qu'ils intègrent le discours des 
générations précédentes, soit qu'ils sont rejetés parce que sur-appropriés par la culture dominante » (p. 121).

9 Avec son argumentation selon laquelle l'AAE constitue le cœur de l'identité culturelle africaine-américaine, Marcyliena Morgan poursuit son cheminement jusqu'au dernier chapitre dont s'inspire le titre de l'ouvrage. Là, elle se concentre sur deux questions essentielles. L'un de ses informateurs affirme : « les Noirs croient en l'éducation - c'est la seule chose en quoi nous croyons ". D'où la première question qui est de savoir «comment le système éducatif comprend-il et prend-il en compte les pratiques culturelles et langagières des Africains-Américains?»(p.134). La réponse de l'auteure est que, tragiquement, il ne s'en préoccupe pas. Depuis l'intégration obligée des écoles publiques, toutes les tentatives pour considérer les besoins spécifiques des enfants africains-américains ont échoué, la dernière étant, en 1996, celle du Oakland School Board of Education pour promouvoir une politique d'enseignement de la langue destinée aux locuteurs de l'AAE ou de l'Ebonics. Morgan attribue cet échec aux clivages, à la fois dans la communauté africaine-américaine et dans le grand public, en ce qui concerne les objectifs de l'alphabétisation et les projets visés par l'éducation. D'une part, les Africains-Américains sentent les perspectives d'avenir pour leurs enfants menacées, tandis que de l'autre, la population en général rejette tout ce qui correspondrait à des privilèges accordés - en dépit de l'objectif clairement déclaré de donner une compétence en GE. Des deux côtés, il y a eu un échec de communication.

10 Sa seconde question concerne la vision de certains intellectuels selon laquelle, pour les étudiants africains-américains, le fait de dévaluer ou de s'opposer à l'éducation officielle représente le moyen de protéger une identité noire et d'éviter le stéréotype les désignant comme moins intelligents que les Blancs. Bien que reconnaissant une certaine puissance à cet argument, Marcyliena Morgan apporte cependant un élément qui permet d'étayer un point de vue différent, à savoir que les étudiants africainsaméricains apprécient l'éducation officielle mais, même quand ils y excellent, ils éprouvent parallèlement le besoin de "conserver une position sociale valorisée à travers l'usage de l'AAE et du GE, les choix musicaux et l'évitement des clichés du “pauvre type" » (p. 150). En d'autres termes, l'opposition à l'éducation officielle est plus simulée que réelle, puisque les enfants africains-américains optent pour une " éducation non conformiste » et évitent de devenir "l'idiot instruit ». C'est seulement quand l'enseignement de la langue correspondra aux besoins culturels des AfricainsAméricains, comme le confirment tous les artistes de hip-hop parlant d'éducation, que la promesse de l'éducation américaine sera réalisée.

11 Language, Discourse and Power in African American Culture est un tour d'horizon très condensé de l'histoire et des pratiques de l'AAE et des politiques lui assignant sa place dans la société américaine. L'utilisation par l'auteure d'anecdotes de terrain ou personnelles ajoutent couleurs et vie à ce qui n'aurait pu être autrement qu'une argumentation ennuyeuse. Elles servent à transformer l'argument en un récit, en une narration qui s'élabore continûment à partir de la mémoire des " premiers temps » et des politiques de positionnement au sein d'une société multiethnique attachée, du moins à première vue, à l'égalitarisme. Le livre conteste le stéréotype du discours africain-américain considéré comme une tentative imparfaite pour s'exprimer en anglais courant. Il argumente de façon convaincante sur son statut en tant que symbole de la culture africaine-américaine, développé au travers d'un processus de créolisation. Néanmoins, c'est précisément pour cette raison que ce livre sera accueilli avec un 
certain scepticisme, même de la part d'Africains-Américains, ce dont l'auteure est tout à fait consciente. "C'est pourquoi », déclare-t-elle, "les gens qui ne respectent pas l' African American English (AAE) me font peur, particulièrement s'ils sont noirs. Je veux dire, comment sauront-ils qu'on leur a transmis le secret? Que se passera-t-il s'ils "manquent le coche" ?» (p. 3). Et si c'était l'auteure qui le manquait? Le plus tragique serait que ce dialecte qui encode le secret de la résistance au racisme américain et qui a tellement contribué au développement et à l'extension de la culture américaine, doive, pour finir, être complètement gommé par les politiques d'assimilation. 